\title{
Pharmacokinetic comparison
} of inhaled fixed combination $v s$. the free combination of beclomethasone and formoterol pMDIs in
asthmatic children

Bo L. K. Chawes, ${ }^{1}$ Annalisa Piccinno, ${ }^{2}$ Eskil Kreiner-Møller, ${ }^{1}$

Nadja H. Vissing, ${ }^{1}$ Porntiva Poorisrisak, ${ }^{1}$ Li Mortensen, ${ }^{1}$ Erik Nilson, ${ }^{1}$ Amalie Bisgaard, ${ }^{1}$ Anna Dossing, ${ }^{1}$ Maja Deleuran, ${ }^{1}$ Nanna L. Skytt, ${ }^{1}$ Nasim Samandari, ${ }^{1}$ Francesco Sergio, ${ }^{2}$ Giorgia Ciurlia, ${ }^{2}$ Gianluigi Poli, ${ }^{2}$ Daniela Acerbi ${ }^{2} \&$ Hans Bisgaard ${ }^{1}$

${ }^{1}$ Copenhagen University Hospital, Copenhagen Prospective Studies on Asthma in Childhood, Health Sciences, University of Copenhagen \& Danish Pediatric Asthma Center, Gentofte, Denmark and ${ }^{2}$ Corporate Clinical Development, Chiesi Farmaceutici S.p.A., Parma, Italy

\section{WHAT IS ALREADY KNOWN ABOUT} THIS SUBJECT

- The fixed combination of beclomethasone dipropionate and formoterol pMDI is marketed as Foster ${ }^{\circledR} 100 / 6 \mu \mathrm{g}$ for use in adults with asthma. Foster ${ }^{\circledR}$ is now being developed in the lower strength $(50 / 6 \mu \mathrm{g})$ to provide an appropriate dosage for children with asthma.

\section{WHAT THIS STUDY ADDS}

- This study demonstrates that beclomethasone dipropionate and formoterol pharmacokinetic and pharmacodynamic effects are non-superior after administration of the two actives as fixed vs. the free combination in asthmatic children aged 5-11 years.

\section{AIM}

The fixed combination of beclomethasone (BDP) and formoterol pressurized metered dose inhaler (pMDI) (Foster ${ }^{\circledR}$, Chiesi Farmaceutici) is being developed in the lower strength (BDP/formoterol: $50 / 6 \mu \mathrm{g}$ ) to provide an appropriate dosage for children with asthma. The aim of this work was to investigate the systemic bioavailability of beclomethasone-17-monoproprionate (B17MP, the active metabolite of BDP) and formoterol after single inhalation of Foster ${ }^{\circledR}$ pMDI $50 / 6 \mu \mathrm{g} v$ s. the free combination of BDP and formoterol pMDIs in asthmatic children.

\section{METHODS}

Children aged 5-11 years old inhaled BDP $200 \mu \mathrm{g}$ and formoterol $24 \mu \mathrm{g}$ as fixed $v$ s. free combination in an open label, randomized, two way crossover single dose study. Blood was collected pre-dose up to $8 \mathrm{~h}$ post-dose for pharmacokinetic evaluation $\left(A \cup C(0, t), A \cup C(0, \infty), A \cup C\left(0,0.5 \mathrm{~h}, C_{\max ,} t_{\max ,} t_{1 / 2}\right)\right.$. Pharmacodynamics included heart rate, plasma potassium, urinary glucose and cortisol excretion. Peak expiratory flow and adverse events were monitored.

\section{RESULTS}

Twenty subjects were evaluable. The systemic exposure of B17MP and formoterol administered as fixed combination did not exceed the free combination: B17MP AUC $(0, t)\left(\mathrm{pg} \mathrm{ml}^{-1} \mathrm{~h}\right)$ ratio test : reference $(90 \% \mathrm{Cl}), 0.81$ $(0.697,0.948)$ and formoterol $\mathrm{AUC}(0, t)\left(\mathrm{pg} \mathrm{ml}^{-1} \mathrm{~h}\right)$ ratio test : reference $0.97(0.85$, 1.10). All pharmacokinetic and pharmacodynamic end points showed non-superiority in favour of the test drug. One adverse event (vertigo) occurred but was not considered treatment-related.

\section{CONCLUSION}

BDP and formoterol pharmacokinetic and pharmacodynamic effects are non-superior after administration of the two actives as fixed $v$ s. the free combination in 5-11-year-old asthmatic children. 


\section{Introduction}

The treatment of children above 5 years of age with asthma as per international guidelines [1] is a stepwise approach based on level of asthma control. The initial prescribed drug at step 1 is an as needed inhaled short acting $\beta_{2}$-adrenoceptor agonist (SABA), whereas inhaled corticosteroids (ICS) are recommended at subsequent steps. If proper asthma control is not gained at step 2 (SABA + low dose ICS), it is recommended to increase the ICS dose or add a leukotriene modifier or a long acting $\beta_{2}$-adrenoceptor agonist (LABA) to achieve optimal long term control of asthma symptoms.

Fixed combinations of ICS/LABA have been approved for use in children with moderate to severe asthma [2]. A recent meta-analysis of 30 trials (three paediatric and 27 adult) [3] showed that fixed combinations of ICS/ LABA led to greater improvement in lung function and enhanced symptom control compared with higher doses of ICS.

This study investigates Foster ${ }^{\circledR}$ pressurized metered dose inhaler (pMDI), a fixed formulation of the ICS beclomethasone dipropionate (BDP) and the LABA formoterol fumarate, now being developed in the lower strength $50 / 6 \mu \mathrm{g}$ to permit an appropriate dosage administration in 5-11-year-old children.

The main objective of this study was to confirm that the systemic exposure of beclomethasone-17monopropionate (B17MP, the active metabolite of BDP), and formoterol after inhalation of four puffs of Foster ${ }^{\circledR}$ $50 / 6 \mu \mathrm{g}$ pMDI was not higher [4] compared with the free combination of approved BDP and formoterol pMDIs, i.e. non-superiority. Additional pharmacokinetic parameters and the systemic effects and thus the general safety and tolerability profile of BDP/B17MP and formoterol were assessed.

\section{Methods}

\section{In vitro study}

To support the in vivo pharmacokinetic and pharmacodynamic comparisons of BDP/formoterol vs. both components administered separately, the in vitro deposition of BDP $50 \mu \mathrm{g}$ and formoterol $6 \mu \mathrm{g}$ from Foster ${ }^{\circledR}$ was compared with that of BDP from Qvar ${ }^{\circledR} 50 \mu \mathrm{g}$ and formoterol $6 \mu \mathrm{g}$ from Atimos ${ }^{\circledR}$. The mass median aerodynamic diameter and fine particle dose of BDP and formoterol were determined using an Andersen Cascade Impactor (Copley Instruments, Nottingham, UK) operated at $28.3 \mathrm{I} \mathrm{min}^{-1}$, with 10 shots per determination. Fine particle dose was defined as the fraction of particles $<4.7 \mathrm{~mm}$. The drug deposition profile was assessed with a fully validated highperformance liquid chromatography-UV method, with a limit of quantification of $8.4 \mathrm{ng} \mathrm{ml}^{-1}$ for formoterol and $24 \mathrm{ng} \mathrm{ml}^{-1}$ for BDP and CV\% lower than $0.45 \%$ for formoterol and lower than $0.32 \%$ for BDP.

\section{In vivo study design}

The study was an open label, randomized, two way crossover, single dose study, with two active treatment periods. A wash out period of at least 7 days and maximum 3 weeks separated each study drug administration. A screening visit, including medical history, physical examination and lung function assessment, took place within 2 to 21 days before the first drug administration. A medical discharge procedure was performed within 7 days after the last drug administration.

\section{Subjects}

Children aged 5-11 years with a documented clinical history of asthma followed as outpatients at the Children's Asthma Clinic, Copenhagen, Denmark, who were able to use a pMDI with a spacer properly, were invited to participate in the study. Asthma was diagnosed by the study physicians according to the GINA guidelines based on symptoms typical of childhood asthma (i.e. exercise induced symptoms, prolonged nocturnal cough, recurrent cough outside common cold and symptoms causing wakening at night) requiring intermittent rescue use of inhaled $\beta_{2}$-adrenoceptor agonist and/or inhaled corticosteroid to obtain symptom control. We aimed for an equal distribution between younger ( $5-8$ years) and older children (9-11 years). Exclusion criteria were exacerbation of asthma symptoms or lower respiratory tract infection within the previous 4 weeks, obesity (i.e. $\geq 97 \%$ weight percentile) and past or present diagnoses of cardiovascular, renal or liver disease.

\section{Ethics}

The study was conducted in accordance with Good Clinical Practice and the current guidelines of the Revised Declaration of Helsinki. The local Ethics Review Committee (Research Ethics Committees for the Region Midtjylland) and the Danish National Board of Health provided formal approval of the study. Written informed consent was obtained from the parents/guardians at the screening visit.

\section{Test and reference treatment}

The test drug was Foster ${ }^{\circledR} 50 / 6 \mu \mathrm{g}$ pMDI (BDP $50 \mu \mathrm{g}$ and formoterol $6 \mu \mathrm{g}$ ) with hydrofluoroalkane (HFA) excipient administered via the AeroChamber Plus ${ }^{\mathrm{TM}}$ spacer. Total test dose was BDP $200 \mu \mathrm{g}$ and formoterol $24 \mu \mathrm{g}$. The reference treatment was licensed BDP $50 \mu \mathrm{g}$ pMDI (Qvar $\left.{ }^{\circledR}\right)$ and formoterol $6 \mu \mathrm{g}$ pMDI (Atimos ${ }^{\circledR}$ ) both delivered via the AeroChamber Plus $^{\mathrm{TM}}$ spacer (Trudell Medical International, Ontario, Canada). Qvar ${ }^{\circledR}$ was chosen as reference drug for Foster ${ }^{\circledR}$ as both are extra-fine particle pMDIs. The reference drug $\mathrm{Qvar}^{\circledR}$ is licensed in children $>5$ years in many EU countries, including Denmark with the trade name of Aerobec $^{\circledR}$. Total reference dose was BDP $200 \mu \mathrm{g}$ and formoterol $24 \mu \mathrm{g}$. The study was performed with the supratherapeutic dosage of BDP/formoterol $200 / 24 \mu \mathrm{g}$ in order to 
assess properly the plasma profile of the analytes during the elimination phase taking into account that especially formoterol plasma concentrations are very low even at the maximum daily dosage of $24 \mu \mathrm{g}$.

At the screening visit and prior to the study drug administrations, the subjects practiced the inhalations with placebo pMDIs and the AeroChamber Plus ${ }^{\mathrm{TM}}$ spacer until the investigator judged the technique to be optimal. The patients were instructed to hold their breath for $5 \mathrm{~s}$ following each long inhalation with the spacer and to wait $30 \mathrm{~s}$ before taking the next inhalation. All pMDIs were primed with four puffs prior to administration. Any ICS or fixed combinations of ICS/LABA were paused 3 days prior to study drug administration.

\section{Pharmacokinetics, pharmocodynamics, efficacy and safety assessment}

The children attended the clinic at $08.00 \mathrm{~h}$ after having fasted overnight and remained fasted until $2 \mathrm{~h}$ postdosing. The children were asked to empty their bladder before study drug administration. Before inhalation of the study drug an intravenous cannula was inserted into a cubital vein anaesthetized with lidocaine gel $\left(\mathrm{Emla}^{\circledR}\right)$ for collection of blood samples.

Pharmacokinetic evaluation Seven blood samples of about $1.5 \mathrm{ml}$ for the determination of formoterol in plasma in the 0-8 $\mathrm{h}$ interval after dosing (pre-dose, $30 \mathrm{~min}, 1,2,4,6$ and $8 \mathrm{~h}$ post-dose) were collected into vacuum tubes containing lithium heparin. At the same time points, seven blood samples of about $1.5 \mathrm{ml}$ were collected for BDP and B17MP assay into vacuum tubes containing EDTA. All samples were immediately chilled (ice bath) and plasma preparation was done within $15 \mathrm{~min}$ after blood collection. The plasma was separated in a refrigerated centrifuge $\left(+4^{\circ} \mathrm{C}\right)$ at $1,097 \times g$ for $15 \mathrm{~min}$ and transferred into prelabelled polypropylene tubes. For stabilizing the formoterol compound, the polypropylene tubes for formoterol were pre-filled with $50 \mu \mathrm{l}$ of citric acid. These tubes were centrifuged before use in order to ensure that the citric acid was at the bottom of the tube.

All tubes were stored at $-80^{\circ} \mathrm{C}$ before shipment on cold dry ice to the laboratory SGS LSS, Wavre, Belgium.

The assay of BDP, B17MP and formoterol was performed using validated high performance liquid chromatography with tandem mass spectrometric detection. The laboratory analyses were carried out following Good Laboratory Practice of the Organization for Economic Cooperation and Development. The limit of quantification (LOQ) was $2 \mathrm{pg} \mathrm{ml}^{-1}$ for formoterol and $50 \mathrm{pg} \mathrm{ml}^{-1}$ for BDP/ B17MP.

Pharmacodynamic evaluation Plasma potassium, heart rate, and cortisol excretion in urine (creatinine adjusted) were evaluated as an index of the study drugs systemic effects.
Seven blood samples of about $1 \mathrm{ml}$ were collected for potassium determination into vacuum tubes containing lithium heparin.

Heart rate was assessed by a pulse oxiometer (Mediaid Inc, Cerritos, CA, USA) measured in supine position after 5 min rest at the seven scheduled times before blood sampling.

Urine was collected from pre-dose until $8 \mathrm{~h}$ post-dose, at each study period for glucose, cortisol and creatinine determination. The urine was kept in a refrigerator until the collection was completed. After homogenization and recording of the total weight, one $10 \mathrm{ml}$ sample for glucose, one $10 \mathrm{ml}$ sample for cortisol assay and one $10 \mathrm{ml}$ sample for creatinine assay was immediately stored at $-80^{\circ} \mathrm{C}$. Determination of cortisol in urine was performed using a radioimmunoassay kit (RIA CT, RADIM), creatinine was determined by an enzymatic colorimetric method and glucose in urine was measured by means of dipstick (COMBUR TEST, Cobas, Roche).

Efficacy evaluation Peak expiratory flow $\left(P E F, \mid s^{-1}\right)$ was evaluated with a handheld peak flow meter (PiKo1, nSpire, Health Inc, CO, USA) at the same time point of the pharmacokinetic assessments.

Safety evaluation Adverse events were recorded according to GCP-ICH and European guidance from signing the informed consent form until the end of the study.

\section{Data analysis}

Pharmacokinetic parameters (area under the concentration-time curve from zero to the last measured time point $(A \cup C(0, t)$, area under the concentration-time curve extrapolated to infinity $\operatorname{A\cup C}(0, \infty)$, maximum observed plasma concentration $\left(C_{\max }\right)$, time to $C_{\max }\left(t_{\max }\right)$ and half-life $\left(t_{1 / 2}\right)$ for BDP, B17MP and formoterol and $\mathrm{AUC}(0,0.5 \mathrm{~h})$ for B17MP and formoterol) were calculated using WinNonlin version 4.1 (Pharsight Corporation, Cary, NC, USA). The treatment difference was tested in an ANOVA model where subject nested within sequence was included as a random effect and sequence, period and treatment were included as fixed effects. To be able to demonstrate that the systemic exposure was not higher for the test product than for the reference product, the upper limit of the $90 \% \mathrm{Cl}$ for the least-square mean ratio between test and reference treatment had to be $<1.25$. All pharmacokinetic variables were log-transformed before the ANOVA, except for $t_{\max }$ and $t_{1 / 2}$ which were compared using the non-parametric Wilcoxon signed rank test.

The treatment difference in plasma potassium $\left(C_{\text {min }}, t_{\text {min }}\right.$, $\operatorname{AUC}(0,8 \mathrm{~h})$ ), urine cortisol (Ae[ $8 \mathrm{~h}$ excretion $] / \mathrm{Ae}_{\text {creat }}[8 \mathrm{~h}$ excretion normalized for $8 \mathrm{~h}$ creatinine excretion]) and heart rate $(A \cup C(0,8 \mathrm{~h}) / 8)$ was analyzed using ANOVA models and Friedman's non-parametric test. Urine glucose was reported as a binary endpoint with number and percentage of patients having values $>30 \mathrm{mg} \mathrm{dl}^{-1}$. PEF values at 
each time point were summarized by treatment using descriptive statistics and trends over time were plotted. All analyses were performed with SAS version 9.2 (SAS Institute, Inc., Cary, NC).

Additional details are outlined in Online Depository S1.

\section{Results}

\section{In vitro study}

The in vitro tests revealed comparable mass median aerodynamic diameter (MMAD) and fine particle dose profiles of BDP and formoterol from Foster ${ }^{\circledR}, \mathrm{Qvar}^{\circledR}$ and Atimos (see online depository).

\section{Study population}

A total of 27 children were screened and 26 were randomized of whom three children were withdrawn before receiving any treatment. Thus the safety population consisted of 23 patients. During the treatment phase of the study, one patient was withdrawn after one treatment period due to difficulties with blood sampling. In two patients, no quantifiable study drug concentration was detected in plasma in one or both treatment phases resulting in 20 children evaluable for pharmacokinetic and pharmacodynamic analysis.

The gender distribution was $78.3 \%$ males and $21.7 \%$ females. The mean age was 9.9 years (SD, 1.3 years) and five subjects were 5-8 years old. All patients had an asthma diagnosis between 2 to 7 years before study entry. All patients had been or were on treatment with a SABA, 16 were treated with ICS and nine received or had received montelukast. Nine children had concomitant allergic rhinitis, three children atopic dermatitis, one child had coeliac disease and one child attention deficit/hyperactivity disorder.

\section{Pharmacokinetics}

B17MP The plasma profile of B17MP is outlined in Figure 1 illustrating that the exposure to the test and reference treatments are comparable and that the mean systemic exposure to the test treatment does not exceed the exposure to the reference treatment. Accordingly, the pharmacokinetic comparison of B17MP in the test vs. reference treatments showed that the upper limit of the confidence intervals were below the pre-specified limit of 1.25 for both the primary end point $(A \cup C(0, t))$ and all secondary continuous variables $\left(A \cup C(0,0.5 \mathrm{~h}), \mathrm{AUC}(0, \infty), C_{\max }\right)$, i.e. nonsuperiority of the test drug was demonstrated (Table 1). The lower limits of the confidence intervals were slightly below the standard limit of 0.8 for $\mathrm{AUC}(0, t)(90 \% \mathrm{Cl}, 0.697$, $0.948)$ and $A \cup C(0,0.5 h)(90 \% \mathrm{Cl} 0.697,0.943)$ suggesting that the treatments are not fully interchangeable. $t_{\max }$ and $t_{1 / 2}$ were also comparable for B17MP in the test vs. reference treatments: $t_{\max ,} 0.517 \mathrm{~h}$ vs. $0.517 \mathrm{~h}, P=0.30 ; t_{1 / 2}, 1.71$ vs. $1.76, P=0.48$.

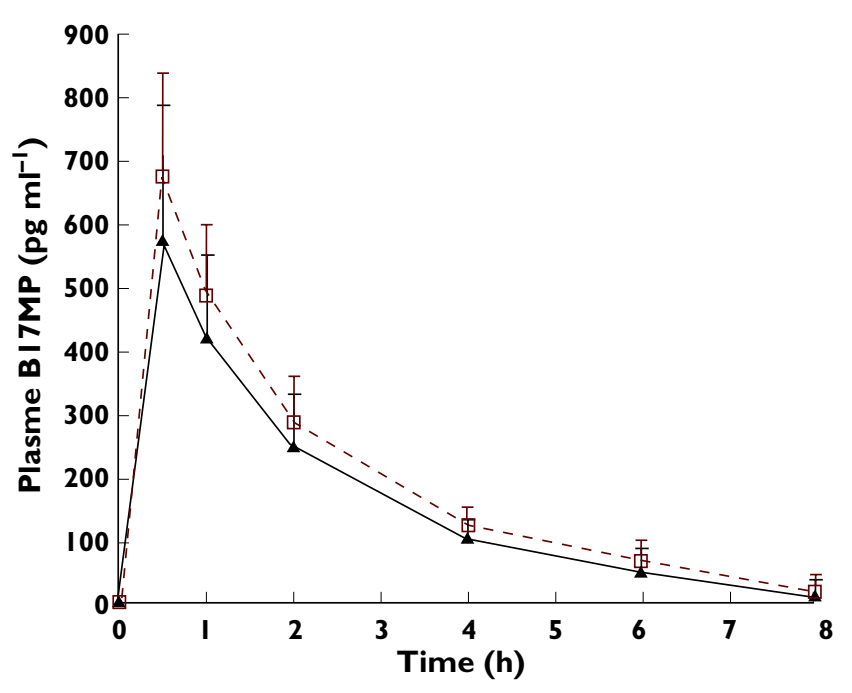

\section{Figure 1}

Mean B17MP plasma profiles from pre-dose $(0 \mathrm{~h})$ till $8 \mathrm{~h}$ post-dose by treatment: Foster ${ }^{\circledR} 50 / 6 \mu \mathrm{g}$ pMDI fixed combination of BDP and formoterol (test, $\rightarrow$ ) vs. the free combination of BDP and formoterol pMDI (reference, $-\square-$ ). $n=20 ; \mathrm{LOQ}=50 \mathrm{pg} \mathrm{ml}^{-1}$

Formoterol The systemic exposure to formoterol is illustrated in Figure 2 which shows that the plasma profiles of the test and reference treatments are fully superimposable. The point estimates (ratio test:reference) for $\operatorname{A\cup C}(0, t), A \cup C(0,0.5 \mathrm{~h}), \operatorname{A\cup C}(0, \infty)$, and $C_{\max }$ were close to 1 and the corresponding upper limits of the $90 \%$ confidence intervals were below the pre-specified 1.25 upper limit suggesting that the systemic exposure of the test treatment did not exceed that of the reference treatment (Table 2). There were no significant differences for $t_{\max }$ and $t_{1 / 2}$ between test and reference treatment: $t_{\max }, 0.517 \mathrm{~h} v \mathrm{~s}$. $0.517 \mathrm{~h}, P=0.97 ; t_{1 / 2}, 3.30$ h vs. $3.49 \mathrm{~h}, P=0.86$.

$B D P$ The short half-life of BDP compromised the pharmacokinetic evaluation of plasma concentrations as only few of the samples, drawn at $0.5 \mathrm{~h}$ post-dose, had measurable concentrations. Measurable concentrations at this time point were only present in five patients after administration of reference, in two patients after both test and reference administration and in one patient only after administration of the test product. Therefore, evaluation of pharmacokinetics parameters was not relevant for BDP.

Age-stratified analysis B17MP and formoterol plasma profiles of test and reference treatment and pharmacokinetic parameters were evaluated in the two subgroups of children aged 5-8 and 9-11 years showing comparable results, thus indicating that the pharmacokinetics of B17MP and formoterol were not affected by age in the 5-11 year range (Figures E1-E2 and Tables E1-E2 online). 


\section{Table 1}

Pharmacokineticanalysis of B17MP in Foster ${ }^{\circledR} 50 / 6 \mu \mathrm{g}$ pMDI fixed combination of BDP and formoterol (test treatment) vs. the free combination of BDP and formoterol pMDI (reference treatment)

\begin{tabular}{|c|c|c|c|c|}
\hline \multirow[b]{2}{*}{ B17MP } & \multicolumn{4}{|c|}{ Adjusted geometric mean $(95 \% \mathrm{Cl})$} \\
\hline & Test & Reference & Ratio Test : Reference & $90 \% \mathrm{Cl}$ for ratio \\
\hline $\operatorname{AUC}(0, t)\left(p g \mathrm{ml}^{-1} \mathrm{~h}\right)$ & 1157.2 & 1423.4 & 0.81 & $0.697,0.948$ \\
\hline $\operatorname{AUC}(0, \infty)\left(p g \mathrm{l}^{-1} \mathrm{~h}\right)$ & 1328.0 & 1605.6 & 0.83 & $0.724,0.945$ \\
\hline$A \cup C(0,0.5 h)\left(p g \mathrm{ml}^{-1} \mathrm{~h}\right)$ & 137.6 & 169.7 & 0.81 & $0.697,0.943$ \\
\hline$C_{\max }\left(\mathrm{pg} \mathrm{ml}^{-1}\right)$ & 532.0 & 653.1 & 0.82 & $0.701,0.947$ \\
\hline
\end{tabular}

The estimates are the adjusted least squares mean estimates on the natural log scale; the adjusted geometric means are the back-transformed values. AUC $=$ Area under the plasma drug concentration-time curve; $\operatorname{AUC}(0, \infty)$ is $A \cup C$ extrapolated to infinity. $C_{\max }=$ maximum observed plasma concentration.

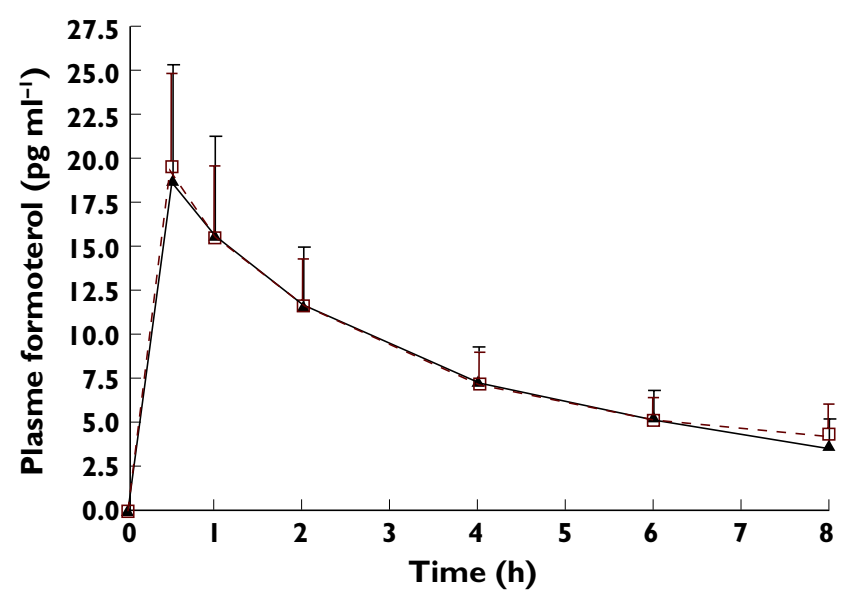

\section{Figure 2}

Mean formoterol plasma profiles from pre-dose $(0 \mathrm{~h})$ till $8 \mathrm{~h}$ post-dose by treatment: Foster ${ }^{\circledR} 50 / 6 \mu \mathrm{g}$ pMDI fixed combination of BDP and Formoterol (test, $\rightarrow$ ) vs. the free combination of BDP and formoterol pMDI (reference, $-\square-$ ). $n=20 ; \mathrm{LOQ}=2 \mathrm{pg} \mathrm{ml}^{-1}$

\section{Pharmacodynamics}

Plasma potassium Plasma potassium concentrations were similar after test and reference treatments: the mean $\operatorname{AUC}(0,8 \mathrm{~h})$ was 31.1 and $30.71 \mathrm{mEq} \mathrm{I}^{-1} \mathrm{~h}^{-1}$ for test and reference (ratio test : reference $1.01 ; 95 \% \mathrm{Cl} 0.98,1.05$ ), mean $C_{\min }$ was $3.7 \mathrm{mEq} \mathrm{I}^{-1}$ for both treatments (ratio test : reference $1.00 ; 95 \% \mathrm{Cl} 0.97,1.03)$ and mean $t_{\min }$ was 3.4 and $3.3 \mathrm{~h}$ (Friedman's test, $P=0.80$ ) (Table E3 and Figure E3 online). The mean $C_{\min }$ value was within the normal range for plasma potassium.

Urine cortisol The cortisol : creatinine ratio varied considerably among patients, but was comparable between test and reference treatments: the mean cortisol:creatinine ratio was $61.0 \mu \mathrm{g} \mathrm{g}^{-1}$ and $60.6 \mu \mathrm{g} \mathrm{g}^{-1}$ for test and reference, respectively (ratio test : reference $1.12 .95 \% \mathrm{Cl} 0.87,1.44$ ) (Table E4 and Figure E4 online).

Urine glucose Urine glucose concentrations were less than $30 \mathrm{mg} \mathrm{dl}^{-1}$ (normal range $0-30 \mathrm{mg} \mathrm{dl}^{-1}$ ) in all patients except two, who hadd glucose concentrations of $33 \mathrm{mg} \mathrm{dl}^{-1}$ and $67 \mathrm{mg} \mathrm{dl}^{-1}$ after test administration. Since study patients were not subjected to alimentary restrictions and glucose-containing food was permitted, these findings were deemed not clinically relevant.

Heart rate Heart rate was within the expected ageadjusted range (50-120 beats $\mathrm{min}^{-1}$ ) for all patients during both treatments. The average heart rate $\operatorname{AUC}(0,8 \mathrm{~h}) / 8$ was similar after test and reference treatments: 82.5 and 81.8 beats $\mathrm{min}^{-1}$, respectively (ratio test: reference 1.01, $95 \% \mathrm{Cl} 0.98,1.04)$. The mean profile of heart rate over time by treatment outlined in Figure 3 shows an expected rise in heart rate after administration of both treatments from pre-dose till $0.5 \mathrm{~h}$ post-dose.

\section{Efficacy evaluation}

There was an increase in PEF after both treatment administrations which was maintained throughout the period of measurement from pre-dose till $8 \mathrm{~h}$ post-dose (Figure 4).

\section{Safety evaluation}

Only one adverse event occurred during the study (vertigo) after administration of test treatment. The event was considered of mild intensity and not related to the study drug.

\section{Discussion}

\section{Main finding}

After four puffs of Foster ${ }^{\circledR} 50 / 6 \mu \mathrm{g}$ pMDI administration, the B17MP and formoterol systemic exposure was not superior to the systemic exposure observed after BDP and formoterol administration as free combination in asthmatic children aged 5-11 years. Pharmacodynamic effects were similar after administration of the two actives as fixed or free combination supporting a comparable safety profile.

\section{Strengths of the study}

The randomized crossover design was chosen for this trial as it is well established as the most effective way for 


\section{Table 2}

Pharmacokinetic analysis of formoterol in Foster ${ }^{\circledR} 50 / 6 \mu \mathrm{g}$ pMDI fixed combination of BDP and formoterol (test treatment) vs. the free combination of BDP and formoterol pMDI (reference treatment)

\begin{tabular}{|c|c|c|c|c|}
\hline \multirow[b]{2}{*}{ Formoterol } & \multicolumn{4}{|c|}{ Adjusted geometric mean (95\% Cl) } \\
\hline & Test & Reference & Ratio Test : Reference & $90 \%$ Cl for ratio \\
\hline$A \cup C(0, t)\left(p g \mathrm{ml}^{-1} \mathrm{~h}\right)$ & 64.5 & 66.5 & 0.97 & $0.85,1.10$ \\
\hline 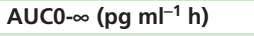 & 85.0 & 87.5 & 0.97 & $0.84,1.12$ \\
\hline AUCO-0.5 h (pg ml $\left.{ }^{-1} \mathrm{~h}\right)$ & 4.5 & 5.0 & 0.91 & $0.77,1.06$ \\
\hline$C_{\max }\left(\mathrm{pg} \mathrm{ml}^{-1}\right)$ & 17.6 & 19.2 & 0.92 & $0.78,1.08$ \\
\hline
\end{tabular}

The estimates are the adjusted least squares mean estimates on the natural log scale; the adjusted geometric means are the back-transformed values. AUC $=$ Area under the plasma drug concentration-time curve; $\operatorname{AUC}(0, \infty)$ is AUC extrapolated to infinity. $C_{\max }=$ maximum observed plasma concentration.

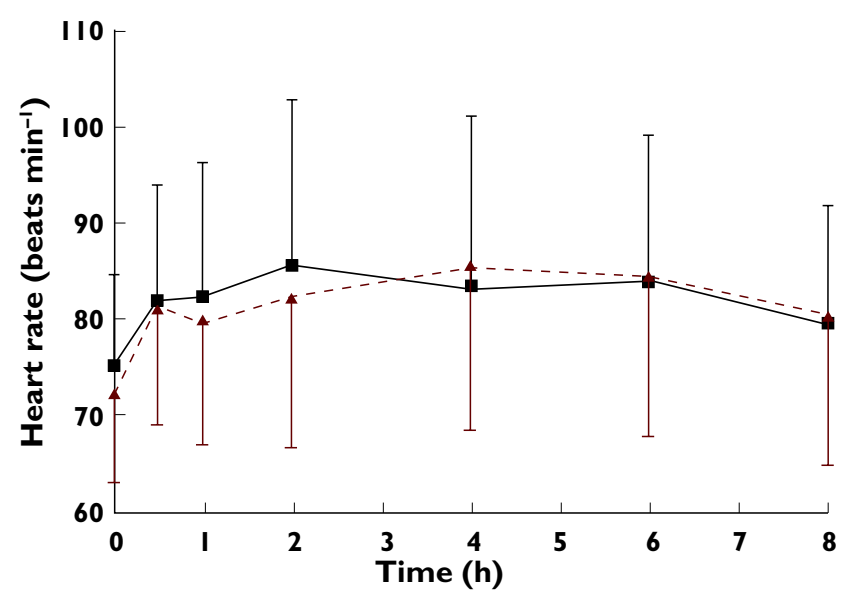

Figure 3

Mean profile diagram of heart rate from pre-dose $(0 \mathrm{~h})$ till $8 \mathrm{~h}$ post-dose by treatment: Foster ${ }^{\circledR}$ 50/6 $\mu \mathrm{g}$ pMDI fixed combination of BDP and formoterol (test, -- ) vs. the free combination of BDP and formoterol pMDI (reference, $-\mathbf{A}^{-}$). $n=20$

comparison of pharmacokinetic parameters of two similar treatments [5]. With the included minimum wash out period of 7 days there was no risk of carry over effect, taking into account five times the terminal half-life [4], which is the main potential disadvantage of the crossover study design.

The study treatment was given in the morning at approximately same time $(08.00-10.00 \mathrm{~h})$ for both treatment periods in order to minimize any circadian variation in pharmacodynamic and pharmacokinetic parameters [6]. Furthermore, the participants were carefully trained in the inhalation technique prior to any study drug administration to assure fully comparable treatment periods.

In order to prevent any kind of contamination, the administration of the study drug was made in a dedicated room well separated from the blood sampling station and the on-site laboratory. In addition, subjects and the physician administering the study drug wore special protective coats and gloves, which were removed before blood sam-

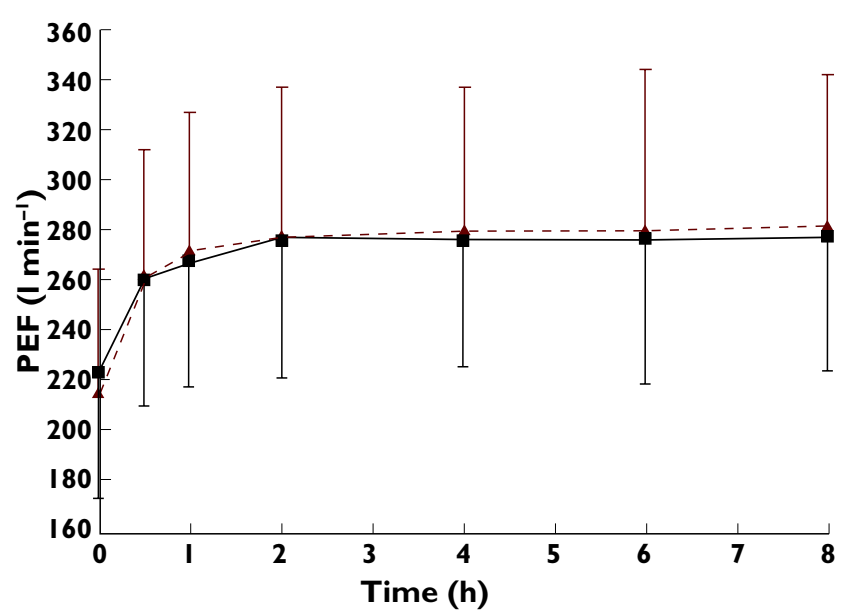

\section{Figure 4}

Mean profile diagram of peak expiratory flow (PEF) from pre-dose $(0 \mathrm{~h})$ till $8 \mathrm{~h}$ post-dose by treatment: Foster ${ }^{\circledR} 50 / 6 \mu \mathrm{g}$ pMDI fixed combination of BDP and formoterol (test, - -) vs. the free combination of BDP and formoterol pMDI (reference, $-\mathbf{-}$ ). $n=20$

pling. Also, the physician administering the inhalations was not allowed to participate in the blood sampling procedures.

Consistency in the study related procedures was assured as a small dedicated and trained team with special paediatric competences performed all the procedures according to standard operating procedures.

\section{Limitations of the study}

Due to the unease of withdrawing blood samples from very young children, we were only able to enrol six patients aged 5-8 years instead of the planned 10 children. The primary statistical analysis was performed on all the 20 children aged 5-11 years. A subgroup equal to $30 \%$ of the total population was considered sufficient to represent the 5-8-year-old subgroup.

Two subjects, who completed the study per protocol, had no quantifiable study drug concentration detectable in plasma in one or both treatment phases. This is presum- 
ably due to poor inhalation technique which to some degree is expected when investigating such young subjects.

\section{Interpretation}

This study showed that the systemic bioavailability of inhaled BDP and formoterol as the fixed combination was not superior in terms of systemic exposure than the free combination of the active substances in children aged 5-11 years. Inhalation of the fixed vs. the free combination of BDP $200 \mu \mathrm{g}$ and formoterol $24 \mu \mathrm{g}$ resulted in similar pharmacodynamic effects and only one adverse event of mild intensity (vertigo) occurred in one subject which was not considered treatment related. Therefore, the novel lower strength fixed combination of BDP $50 \mu \mathrm{g}$ and formoterol $6 \mu \mathrm{g} \mathrm{pMDI}$ is considered appropriate for treatment of childhood asthma in 5-11-year-old children.

The fixed combination of BDP and formoterol pMDI is marketed as Foster ${ }^{\circledR}$ 100/6 $\mu \mathrm{g}$ (Chiesi Farmaceutici) for use in adults with asthma. The data from the current childhood study may now permit an appropriate dosage administration to children aged 5-11 years. The lower limits of the confidence intervals for $\operatorname{BDP} \operatorname{AUC}(0, t)$ and $\operatorname{AUC}(0,0.5 \mathrm{~h})$ were slightly below the standard lower limit of equivalence (80\%). However, for locally acting medicinal products according to the Guideline on the Investigation of Bioequivalence [4], systemic exposure is relevant for safety and therefore the demonstration that the systemic exposure is not higher for the test product than for the reference product should be obtained while no criteria are recommended for lower limit of the $90 \%$ confidence intervals.

The in vitro comparison showed that the ICS and LABA component of Foster 50/6 $\mu \mathrm{g}$ pMDI has similar particle size as the BDP extrafine particles in $\mathrm{Qvar}^{\circledR}$ and formoterol in Atimos ${ }^{\circledR}$. Bioequivalence has been demonstrated between Foster $^{\circledR} 100 / 6 \mu \mathrm{g}$ pMDI and Qvar $100 \mu \mathrm{g}$ [7] and dose proportionality in the $50-100 \mu \mathrm{g}$ dose range $[8,9]$. Therefore, the efficacy and safety data gathered with $\mathrm{Qvar}^{\circledR}$ in children at the doses of $100-200 \mu \mathrm{g} \mathrm{day}^{-1}$ [9] support the present dose selection for Foster ${ }^{\circledR} 50 / 6 \mu \mathrm{g}$ in children. For the LABA component, formoterol is approved in children at daily doses of 12 and $24 \mu \mathrm{g}$. Several studies conducted with formoterol at a daily dose of $24 \mu \mathrm{g}$ in children with asthma have shown that the treatment is effective and well tolerated [10-12]. In the current study, no study drugrelated safety issues arose after administration of Foster ${ }^{\circledR}$ $50 / 6 \mu \mathrm{g}$ which is in line with the above mentioned studies of BDP and formoterol and further supports the safety of the selected dosage regimen.

Foster ${ }^{\circledR} 50 / 6 \mu \mathrm{g}$ pMDI for use in children with asthma aged 5-11 years may help gain proper asthma control and increase treatment compliance for children with asthma not controlled with low dose ICS and as-needed SABA. However, subscription of any fixed combination of LABA and ICS should only be done by an asthma specialist.
In conclusion, inhalation of Foster ${ }^{\circledR} 50 / 6 \mu \mathrm{g}$ pMDI containing the fixed combination of BDP and formoterol compared with inhalation of the same dosage of the free combination of the two active treatments in children aged 5-11 years showed non-superiority of systemic exposure and a comparable pharmacodynamic and safety profile.

\section{Contributions}

$B C, E K M, N V, P P, L M, E N, A D, M D, A B, N S, N S, H B$ are responsible for data acquisition, analysis, interpretation and writing the manuscript. AP, FS, GC, GP, DA were responsible for data analysis, interpretation and writing of the manuscript. All co-authors have contributed substantially to the analyses and interpretation of the data, and have provided important intellectual input and approval of the final version of the manuscript.

\section{Competing Interests}

All authors have completed the Unified Competing Interest form at http://www.icmje.org/coi_disclosure.pdf (available on request from the corresponding author) and declare $B C$ has received payment from Chiesi Pharmaceutici S.p.A. in excess of 10.000Euro for consulting and travel to the ERS congress was funded by Chiesi Pharmaceutici S.p.A. HB has received an honorarium in excess of 10.000 Euro for consulting. AP, FS, GC, GP, DA are employed at Chiesi Pharmaceutici S.p.A. EKM, NHV, PP, LM, EN, AD, AB, $M D, N L S$ and NS had no support from any organization for the submitted work.

Chiesi Farmaceutici S.p.A. funded the study.

\section{REFERENCES}

1 Global Initiative for Asthma (GINA), National Institute of Health, National Heart Lung and Blood Institute (NHLBI) / World Health Organisation (WHO). Global strategy for asthma management and prevention. 2012. Workshop Report, updated 2011. Available at http://www. ginasthma.org (last accessed 15 May 2012). Ref Type: Generic.

2 Alan \& Hanbury Ltd. Seretide Summary of Product Characteristics; Symbicort Summary of Product Characteristics. 2012. Available at http://www.medicines. org.uk/emc/medicine/ (last accessed 15 May 2012). Ref Type: Generic.

3 Greenstone IR, Ni Chroinin MN, Masse V, Danish A, Magdalinos $\mathrm{H}$, Zhang X, Ducharme FM. Combination of inhaled long-acting beta2-agonists and inhaled steroids versus higher dose of inhaled steroids in children and adults with persistent asthma. Cochrane Database Syst Rev 2005; (4)CD005533. 
4 European Medicines Agency (EMEA). Guideline on the Investigation of Bioequivalence. 2012. Doc. Ref.: CPMP/EWP/QWP/1401/98 Rev. 1/ Corr ** - EMA - 2010. Ref Type: Generic.

5 Jones B, Kenward M. Design and Analysis of Cross-Over Trials, 2nd edn. London: Chapman and Hall, 2003.

6 Kennaway DJ, Royles P. Circadian rhythms of 6-sulphatoxy melatonin, cortisol and electrolyte excretion at the summer and winter solstices in normal men and women. Acta Endocrinol (Copenh) 1986; 113: 450-6.

7 Piccinno A, Poli G, Acerbi D, Burton I, Druart X. Pharmacokinetics and pharmacodynamics of a new beclomethasone dipropionate and Formoterol CFC-free fixed combination in healthy volunteers. 2007. Poster presented at the European Respiratory Society, Stockholm, Sweden. Ref Type: Abstract.

8 Poli G, Collarini S, Acerbi D, Fantini M, Usberti F, De Decker M. Dose linearity of beclometasone dipropionate (BDP) in a pMDI BDP plus Formoterol Fixed Combination. 2010. Poster presented at the European Respiratory Society, Barcelona, Spain. Ref Type: Abstract.

9 van Schayck CP, Donnell D. The efficacy and safety of QVAR (hydrofluoroalkane-beclometasone diproprionate extrafine aerosol) in asthma (Part 2): clinical experience in children. Int J Clin Pract 2004; 58: 786-94.
10 Berger WE, Leflein JG, Geller DE, Parasuraman B, Miller CJ, O'Brien CD, O'Dowd L. The safety and clinical benefit of budesonide/formoterol pressurized metered-dose inhaler versus budesonide alone in children. Allergy Asthma Proc 2010; 31: 26-39.

11 Eid NS, Noonan MJ, Chipps B, Parasuraman B, Miller CJ, O'Brien CD. Once- vs twice-daily budesonide/formoterol in 6 to 15 -year-old patients with stable asthma. Pediatrics 2010; 126: e565-e575.

12 Pearlman DS, Kottakis J, Till D, Della CG. Formoterol delivered via a dry powder inhaler (Aerolizer): results from long-term clinical trials in children. Curr Med Res Opin 2002; 18: 445-55.

\section{Supporting Information}

Additional Supporting Information may be found in the online version of this article at the publisher's web-site:

Online depository S1. Pharmacokinetic comparison of inhaled fixed combination vs. the free combination of beclomethasone and formoterol pMDls in asthmatic children. 